\title{
De skate pela cidade: quando o importante é (não) competir *
}

\author{
Giancarlo Marques Carraro Machado
}

resumo Este artigo analisa como certos skatistas relacionam suas práticas citadinas às práticas de cidadania a que estão sujeitos (e que buscam ressignificar) na cidade de São Paulo. O skate pode ser considerado uma das práticas esportivas que mais adquiriu visibilidade nos últimos tempos. Apesar de toda a popularidade adquirida, o skate também é motivo de polêmicas por conta dos dissabores oriundos de sua prática em locais tidos como "inapropriados”. Essa e outras atitudes têm motivado intensos debates em São Paulo, levando muitos agentes ligados ao poder público a elaborar certas açôes que visem disciplinar a prática do skate feita nas ruas. Uma dessas açóes é o Circuito Sampa Skate, cuja formatação e mediaçôes estabelecidas para sua realização podem ser vistas como uma forma de resposta do campo das políticas públicas à intensa propagação da modalidade street skate na cidade.

palavras-chave Skate. Espaços urbanos. Sociabilidade. Cidadania. Citadinidade. Antropologia da cidade.

\section{Introdução}

Reformadas, com pavimento lisinho e de concreto, as calçadas da Avenida Paulista atraem cada vez mais skatistas em busca de manobras radicais, lazer e treinamento para campeonatos. Desde o início das obras, há um ano, é comum vê-los desviando de pelo menos 1,7 milhão de pessoas que circulam diariamente pelo local. $\mathrm{O}$ ziguezague dos esportistas assusta os desavisados. Mas, segundo a Subprefeitura da Sé, não há lei que impeça os skatistas de andar nas novas calçadas da Paulista, cujo custo de reforma está orçado em $\mathrm{R}$ \$ 8,1 milhóes. Mas pode haver limite. A subprefeitura avisa que, se houver dano ao patrimônio público, a administração "agirá no sentido de coibir ou educar os esportistas" (SPINOSA, Marcela. Jornal da Tarde, 11 de julho de 2008, grifos meus).

O skate pode ser considerado uma das práticas esportivas que mais adquiriu visibilidade nos últimos tempos. Isso pode ser comprovado, entre tantos casos, pela audiência dada à vários canais de televisão (por meio de programas que exibem competiçóes ao vivo) e pelo retorno financeiro atribuído às muitas empresas que investem em açóes direcionadas aos adeptos e simpatizantes dessa prática. Além do mais, o Instituto Datafolha publicou em 2010, os resultados de uma pesquisa encomendada pela Confederação Brasileira de Skate (CBSk), cujo objetivo principal era medir a penetração de praticantes do skate nos lares brasileiros, bem como obter o perfil dos mesmos. Os resultados contabilizam mais de 3.860 .000 (três milhôes e oitocentos e sessenta mil) pessoas praticantes, dado que aponta para um aumento de aproximadamente $20 \%$ em relação à mesma pesquisa feita em $2006^{1}$.

São Paulo, por sua vez, é a cidade que mais possui praticantes do skate no país. A 
popularidade é tamanha que, segundo uma pesquisa feita pela prefeitura, o skate figura como o segundo esporte mais praticado em escolas municipais, perdendo somente para o futebol ${ }^{2}$. Com efeito, devido a propagação de sua prática ao longo dos anos, o então vereador Alberto “Turco Loco" (PSDB) instituiu em 3 de agosto de 1995 o Dia Municipal do Skate ${ }^{3}$, comemoração que passou a ser a nível estadual a partir de $2003^{4}$.

Apesar de toda essa popularidade adquirida, o skate é motivo de polêmicas por conta dos dissabores oriundos de seu uso em locais tidos como "inapropriados". Entre as várias modalidades que fazem parte deste universo, uma delas sempre foi alvo de problemas envolvendo uma série de pessoas: trata-se do street skate, ou seja, a prática do skate nas ruas. Os streeteiros, como se denominam os skatistas adeptos dessa modalidade, transitam pela cidade com um olhar apurado para certos equipamentos urbanos, que são vistos como obstáculos a serem superados. Desta forma, um corrimão não serve somente para dar segurança a quem utiliza uma escada, mas também para ser deslizado com o skate. Uma escada não é apenas para se passar de um nível ao outro, mas para ser pulada. Uma escultura não é só para ser olhada e apreciada, mas ao contrário, pode servir como uma inclinação propícia para manobras. Os exemplos se estendem aos bancos, às bordas, às placas de trânsito, etc. Nesse sentido, ao circular pelos espaços urbanos e ao ressignificar as finalidades atribuídas aos seus respectivos equipamentos, os streeteiros "fazem a cidade" (Agier, 2011) a partir de suas próprias experiências e práticas 5 .

A epígrafe anteriormente apresentada demonstra alguns problemas decorrentes da prática do skate na Avenida Paulista, a qual se tornou um dos locais mais visados pelos skatistas da cidade de São Paulo. Para a maioria dos praticantes, andar de skate ${ }^{6}$ nos picos dessa avenida - isto é, em seus equipamentos (corrimãos, bancos, canteiros, etc.) - pode se constituir ora como uma "diversão", ora como um "trabalho"7. Para muitas outras pessoas, ao contrário, essa mesma prática às vezes pode ser vista como uma arruaça, um ato de vandalismo, uma perturbação da "ordem". De acordo com Joseph (2005, p. 119), o espaço público não é um espaço de produção de universais, mas sim "um espaço de hibridação e de excentramento do qual desconfiamos naturalmente". Em razão disso, as variadas lógicas atribuídas aos usos e as apropriaçóes de equipamentos urbanos que, a princípio, não foram planejados visando à prática do skate, em muitos momentos podem resultar em conflitos entre skatistas e outros citadinos, tornando-se, inclusive, caso de polícia. De certa forma, o skatista pode se chocar com outros pedestres na calçada, se machucar, bem como danificar equipamentos, muitos deles privados, ao considerá-los como obstáculos.

Essas atitudes têm motivado intensos debates em São Paulo, levando muitos agentes ligados ao poder público a tentar medidas rigorosas, como a proibição do skate nas calçadas da cidade. ${ }^{8}$ Outros agentes ${ }^{9}$, todavia, entendem que isso não deve ser feito, embora a prática do skate necessite ser regulamentada e disciplinada.

Para delimitar a prática do skate em uma área reservada para esse fim, a prefeitura tem adotado uma série de medidas concretas, como a construção de várias pistas, as quais podem ser encontradas em distintas regióes da cidade. $\mathrm{Na}$ visão de alguns agentes, construí-las seria, possivelmente, uma boa soluçấo diante das disputas pelos usos e apropriaçôes dos equipamentos urbanos. E para incentivar a prática nesses locais considerados "próprios", dentre outros interesses, também foram criadas ações 
De SKATE PELA CIDADE: QUANDO O IMPORTANTE É (NÃO) COMPETIR | I73

visando, mesmo que indiretamente, coibir a prática do skate nas ruas. Uma dessas açóes é o Circuito Sampa Skate - isto é, uma série de campeonatos que acontece ao longo de todo um ano - cuja formatação e mediações estabelecidas para sua realização podem ser vistas como uma forma de resposta do campo das políticas públicas à intensa propagação da modalidade street skate na cidade de São Paulo.

Os organizadores do Circuito Sampa Skate, mediante a tentativa de ampliação daquilo que entendem como cidadania $^{10}$, buscam atingir vários objetivos com a sua realização, tais como: influenciar a prática do skate em pistas, o que implica em tirar os skatistas das ruas; incentivar a disputa esportiva ao longo de todo o ano; manter a mente dos competidores "ocupada” com critérios definidos de participação, etc. Já os skatistas, conforme será evidenciado no decorrer do texto, em suas condiçóes de citadinos ressignificam os sentidos atribuídos a essa percepção de cidadania, e adotam práticas que ora se aproximam, ora se distanciam dos objetivos dos organizadores.

Isaac Joseph (2005, p. 96) já aventara que a passagem da urbanidade à cidadania não corresponde a uma conseqüência natural. Já o citadino não se reduz à figura do transeunte, e, "tampouco coincide obrigatoriamente com a do cidadão (embora possa vir a assumir tal condição" (Frúgoli Jr., 2007, p. 7). Nesse sentido, um dos desafios deste artigo é demonstrar, com base em um trabalho de campo realizado no ano de $2009^{11}$ e através de articulações com teorias concernentes a uma antropologia da cidade (Agier, 2011) ${ }^{12}$, como os skatistas relacionam suas práticas citadinas às práticas de cidadania a que estão sujeitos (e que buscam ressignificar) na cidade de São Paulo. Portanto, em vez de apresentar uma única lógica em torno do universo street skate, pretendo evidenciar etnograficamente os múltiplos sentidos que o perpassam, os quais, embora em alguns momentos pareçam contraditórios, são contínuos e postos em prática de acordo com a situaçãa ${ }^{13}$.

\section{Circuito Sampa Skate: breve histórico}

O Circuito Sampa Skate é o resultado de uma série de açóes contínuas que se deram por meio da parceria entre a iniciativa privada e o poder público. Tudo começou no ano de 2003, quando Márcio Tanabe, um empresário do meio do skate, tinha um skatepark na Rua da Consolaçãao ${ }^{14}$. Na época, a cidade de São Paulo contava com poucas pistas de skate e, além disso, as que existiam não possuíam uma boa estrutura. Buracos no chão e equipamentos danificados eram recorrentes. Aproveitando-se da carência de locais "apropriados" para a prática do skate e também de um considerável número de skatistas na cidade, Tanabe resolveu investir em seu próprio negócio:

Eu ganhava dinheiro praticamente sem fazer muito esforço, porque era um skatepark no centro da cidade. Meu concorrente mais próximo era a Billabong, lá no começo da Rodovia Anchieta, ou, a pista da Saúde, que é uma pista pública, lá próximo à Billabong. Então aqui, neste raio da cidade, não tinha pista de skate. A gente estava com um negócio próspero (Entrevista em 22 de outubro de 2009).

Toda essa prosperidade foi ameaçada com a notícia de que Marta Suplicy (PT, 20012004), então prefeita na época, construiria mais de sessenta pistas de skate espalhadas por diversos pontos da cidade de Sáo Paulo, o que de fato ocorreu. A maioria dessas pistas está 
localizada nos CEUs (Centros Educacionais Unificados) ${ }^{15}$, equipamentos públicos criados pela Secretaria Municipal de Educação da Prefeitura de São Paulo. Com essa benfeitoria, os skatistas não precisariam mais se deslocar por longas distâncias para acessar as poucas pistas públicas, nem pagar para praticar em um espaço privado. Observando seus negócios em crise, Tanabe relatou-me o seguinte:

Como empresário, eu observei e falei: "meu negócio vai rodar! Eu preciso buscar uma alternativa!”. Qual é a principal alternativa? É a força externa que está influenciando diretamente meu negócio? (...) Se esta força é tâo forte que quebra meu negócio, vou procurar esta força e propor uma união. Então, o que eu propus para eles: "você está construindo pistas de skate na periferia. Você precisa dar vida para isto, porque senão uma pista pública é construída, a próxima gestão abandona e a outra destrói”. E destrói porque na gestão do abandono, vai virar ponto de droga. Não porque skatista seja drogado, mas porque a droga faz parte da sociedade e o jovem é vulnerável, está aberto a experiências (Entrevista em 22 de outubro de 2009).

$\mathrm{Na}$ visão de Tanabe, não bastava somente a construção de um espaço para a prática do skate. Seriam necessárias iniciativas que mantivessem a área em constante atividade, caso contrário, o local poderia vir a adquirir o significado estigmatizado acima descrito, reforçando generalizaçóes como "todo skatista é drogado". Tanabe diz ter visto esta situação inúmeras vezes, em que os espaços destinados à prática do skate viraram pontos de uso e comércio de droga. Em conseqüência disso, os próprios moradores do bairro tendem a pressionar o poder público para transformar o local, acabando com o espaço dos skatistas.
Baseado nesse problema, o empresário propôs ao poder público, por meio de sua empresa, a Skate Contest, a criação de eventos nas pistas construídas. Assim nasceu o Circuito Municipal de Skate, evento que consistia em diversos campeonatos realizados em pistas públicas ao longo de todo um ano. Esse circuito, além de promover e estimular a prática do skate em locais "apropriados", também visava identificar skatistas da região onde fosse realizado o campeonato para que eles trabalhassem com os organizadores do evento. Desta forma, a intenção era selecionar alguém com certa influência local e fazer dele, segundo Tanabe, uma "espécie de gerente do espaço público". Diante dessa atribuição, a pessoa seria remunerada para ser monitora no ensino da prática do skate a outros jovens:

Neste evento [Circuito Municipal de Skate] surgiu a ideia de escolher dez skatistas de destaque para iniciar um projeto de capacitação de monitores de skate, parceria entre a ONG Aprendiz e a Skate Contest. Os dez, durante oito meses, passaram por um aprendizado e tornaram-se monitores. Um "monitor" não é bem um professor, é um cara que utiliza o skate com a intençáo de trazer outros jovens para uma convivência com a aplicação do conceito de cidadania e integração social. É a educação fora da sala de aula (Disponível em http://skatecontest. com.br/. Acesso em 30 de abril de 2010).

Com o término do mandato da prefeita Marta Suplicy, a iniciativa, que durou dois anos, foi extinta. Na gestão seguinte, do prefeito José Serra (PSDB, 2005-2006) e em seguida de Gilberto Kassab (DEM, 2006-2008), a Secretaria de Esportes pretendeu dar continuidade às políticas públicas voltadas ao skate. Após 
realizarem um levantamento, os representantes da secretaria entraram em contato com o próprio Tanabe ${ }^{16}$, para que o empresário apontasse aquilo que o skate necessitava na época. As pistas, essenciais para a prática, já não eram mais problema. Então, o skatista necessitava de quê?

O que o skatista de São Paulo precisa é saber exercer seus direitos. Ele tem que se tornar cidadão. Se o skate é o segundo esporte mais praticado entre os jovens e se a gente tem diálogo com este cara que anda de skate, seja ele de dez, vinte, trinta, cinqüenta anos de idade, seja ele da classe a, b, c, $\mathrm{d}$ ou e, a gente consegue conversar com este cara, então, a gente tem uma ferramenta muito boa para, junto com o poder público, exercer a cidadania. Não é só fazer um campeonato de skate para o cara. É fazer um campeonato de skate com tudo que ele tem direito (Márcio Tanabe, entrevista em $22 \mathrm{de}$ outubro de 2009, grifos meus).

E foi pautado na ideia de cidadania, de utilizar o skate enquanto uma ferramenta de inclusão social, que o Circuito Sampa Skate foi criado. Em vigência desde 2005, o circuito conta com uma série de características distintivas - que serão apresentadas nos próximos tópicos - em relação aos outros eventos de skate. A ideia deu certo, virou referência no cenário brasileiro, e ainda permanece até os dias de hoje, atraindo cada vez mais skatistas provenientes das mais diferentes localidades e em busca dos mais variados objetivos.

\section{Skate e cidadania}

Nas relações estabelecidas para a realização do Circuito Sampa Skate há uma série de agentes que atuam como mediadores entre o universo do street skate e o poder público. Entre os envolvidos com a Skate Contest temos a presença de alguns funcionários que possuem, de uma forma ou de outra, uma ligação com a prática do skate, como o caso de Márcio Tanabe. Skatista há vários anos, ele também é o criador de uma das primeiras marcas brasileiras de tênis para skate. Além disso, atuou na mídia especializada, possui um skatepark e organiza diversos campeonatos, tanto amadores quanto profissionais. Em uma conversa, o próprio Tanabe definiu seu papel como mediador:

\begin{abstract}
O meu trabalho foi traduzir [para o poder público], digamos, para a forma culta, o que a galera está falando lá fora. Ou então, o que a galera nem fala, porque não sabe como falar, mas está sentindo. Eu acho que traduzo e por isto eles conseguem atender melhor e entender os caminhos (Entrevista em 22 de outubro de 2009).
\end{abstract}

Esses profissionais, através de suas iniciativas podem vir a se colocar "(...) localmente como mediadores entre escalas, o que implica competências de tradução, lingüística e cultural, e de acessibilidade, por atuação de redes sociais e políticas de alcance extralocal" (Agier, 2001, p. 19). As competências dos envolvidos na organização do Circuito Sampa Skate lhes possibilitam um reconhecimento local, proporcionando status entre os skatistas e até renda suplementar, bem como um reconhecimento mais amplo, no qual são legitimados como representantes de uma diferença. Já pelo lado do poder público, temos outros agentes, funcionários da Secretaria de Esportes. A figura-chave para estabelecer a mediação é Tiago Lobo, coordenador de esportes radicais da Prefeitura de São Paulo, responsável por identificar 
interlocutores no universo heterogêneo do skate que queiram propor iniciativas conjuntas.

Ao construírem o formato do Circuito Sampa Skate, algo evidente para ambas as partes é a preocupação com questóes como cidadania e inclusão social, que devem ser proporcionadas aos competidores. Pautado nessas questóes, o skatista e videomaker Rodrigo "Bocáo" define, de acordo com sua concepção, alguns pontos importantes do evento:

É um campeonato que abre espaço para uma "pá" de gente que está nascendo aqui em São Paulo, tipo a molecada nova que está começando a se destacar, que quer estar no ranking. Aí você acaba sendo lembrado, e vai ajudando bastante a molecada que está aí na periferia. Tem bastante campeonato em todo e qualquer "buraco" de São Paulo (Entrevista em 17 de março de 2010).

$\mathrm{Na}$ mesma linha de pensamento, Rogério "Tilskater" (pai de um skatista competidor) também expressa sua opinião acerca do caráter social das políticas públicas voltadas ao skate:

Ele [o Circuito Sampa Skate] inclui realmente o cidadão. Por exemplo, o moleque de São Miguel vai e anda lá. Provavelmente ele nunca mais vai andar num "Sampa" da vida, ou ele vira um assíduo, como eu já vi vários moleques. Eu acho que essa inclusão social funciona, mas assim: "eu vou estar com a minha galera, eu vou competir e vou estar numa pista". Não é uma pista que você vê todo fim de semana (Rogério "Tilskater". Entrevista em 4 de outubro de 2009, grifos meus).

Realizado desde 2005, o Circuito Sampa Skate é composto por uma série de campeonatos de skate que circulam por diversas regióes - geralmente periféricas - da cidade de São Paulo ao longo de todo o ano, sendo que, em 2009, esteve distribuído por meio de dez etapas. $\mathrm{O}$ caráter itinerante do circuito foi planejado pelos próprios organizadores, o que de certa forma propicia aos skatistas uma circulação pela cidade, para que conheçam outros contextos para fora dos seus e assim criem vínculos com praticantes de diferentes locais. O competidor Alexandre "Nicolau" pontua, com base em sua experiência de participante do evento, que:

É uma oportunidade de você conhecer gente nova, estilos novos, ver o que está acontecendo em outros lugares, o estilo dos moleques que estáo andando, com quem eles estão andando (Entrevista em 26 de março de 2010).

Mas para atender skatistas de diversas partes da cidade foi necessário adotar o seguinte critério:

São Paulo é dividida em trinta e uma subprefeituras. Então a gente fez um mapeamento, pegamos um mapa da cidade e fizemos [as etapas] sempre em subprefeituras vizinhas. Para fazer a regiâo toda. Para não falar: "na Zona Leste, das quinze etapas, têm dez". Não, todas as subprefeituras são atendidas. Para aquele que não tem dinheiro para atravessar a cidade, ele vai a pé, de bike, de ônibus, de carro, de carona, de algum jeito chega... De skate ele vai. Alguma etapa vai passar perto da casa dele. Então ele é democrático também por isto (Tiago Lobo, entrevista em 7 de outubro de 2009).

Desse modo, conforme o andamento do circuito há a possibilidade de uma circulação 
progressiva dos skatistas pela cidade, do ponto de vista do sistema de orientação de cada um. Isso nos leva a pensar, de uma forma mais abrangente, numa fórmula elaborada por Ulf Hannerz (apud Joseph, 2005, p. 117), que considera que "a cidade náo é apenas a acessibilidade acrescentada à diversidade, mas a diversidade na acessibilidade e a acessibilidade na diversidade”.

Como forma de incentivo aos skatistas competidores, todos ainda ganham, gratuitamente, um lanche reforçado. Em cada etapa é montada uma barraca em que são distribuídos sanduíches, sucos e doces. Mas para evitar transtornos na hora da distribuição, o skatista deve comprovar que está competindo. Além disso, outra grande diferença do Circuito Sampa Skate em relação aos demais campeonatos são as inscriçôes, também gratuitas. Para realizá-las é necessário que o skatista esteja na parte da manhâ, no dia da competiçáo de sua categoria, portando alguns documentos como carteira de identidade e comprovante de endereço. Após preencher uma ficha cadastral aceitando todos os termos do regulamento, ele está apto a receber a carteirinha da Federação Paulista de Skate (FPS), o que lhe garante legitimidade como competidor.

Se por um lado as inscriçôes gratuitas possibilitam a participação de muitos competidores, por outro, cada etapa náo oferece nenhum tipo de premiação que possa ser considerada atrativa. De forma simbólica, dão-se troféus e medalhas aos dez melhores de cada categoria, além de uma camiseta com a logomarca do circuito. Todavia, muitos skatistas fazem questão de ir ao Circuito Sampa Skate, contrariando a ideia daqueles que pensam que a premiação é uma das principais finalidades dos competidores:

Quando eu lancei a ideia, eu me lembro que o Ed, da confederação, dizia: "Você é louco? Vai fazer um campeonato com inscrição gratuita?
Vai ter tanto moleque que você vai levar quinze dias para terminar o campeonato". Bom, eu vou fazer um em cada região da cidade. Eu limitava antes, só podia correr na Zona Leste quem morava na Zona Leste. Teve ano que eu fiz mais de um na Zona Leste, mas o cara podia escolher uma etapa. Cada um podia correr somente uma fora dali. Pelo RG a gente cruzava os dados e identificava alguns "furôes". Daí eles viram que não passavam. Aliás, no primeiro ano, o nosso sistema furou várias vezes, e a gente identificava no visual: "Te conheço!” Aí depois a gente veio com um pouco mais de tecnologia que começou a pegar. Aí a gente abriu geral. O Ed dizia que a gente demoraria dias para terminar o evento. Aí eu disse que não íamos dar prêmio em material: "ah, então ninguém vai correr o seu campeonato!”. Então, na verdade é porque as pessoas não estão acostumadas com um padrão. Qualquer coisa nova é muito estranha (Márcio Tanabe, entrevista em 22 de outubro de 2009).

Durante a nossa conversa, Rodrigo "Bocão" apresentou-me, sinteticamente, suas motivaçóes em participar dos campeonatos:

Eu gosto de colar [participar dos campeonatos] porque sempre encontro muitos amigos que náo vejo há tempo. É legal você colar num evento, com todo mundo que está com você. Você consegue mostrar seu skate um pouco, para o pessoal ver que você colocou uma manobra nova no pé: “caramba, está andando bem!”. É para mostrar o skate, estar ali junto com o pessoal. É mais estar com seus amigos (Entrevista em 17 de março de 2010).

Com base na classificação do skatista em cada etapa da competição, são computados 
pontos para um ranking, que define os melhores do circuito. Após todas as etapas acontece o "SP Top 40", um evento que visa recompensar e incentivar os quarenta melhores rankeados, provenientes de algumas categorias. São escolhidos vinte cinco skatistas do "amador I"; cinco do "amador II"; três do "iniciante"; um do "mirim" e mais cinco convidados pela organização. As mulheres não entram nessa lista, pois há um evento feito especialmente para elas, chamado "Skate Para Meninas Street Show". Somente nessas competiçōes é que os skatistas têm a oportunidade de ganhar melhores premiaçóes. Os cinco primeiros colocados podem escolher entre um notebook, uma câmera digital ou uma filmadora, como forma de prêmio pela conquista. Além disso, conforme o prêmio escolhido, o skatista ainda ganha um curso profissionalizante, seja de informática, de fotografia ou de edição de vídeo, capacitando-o para a entrada no mercado de trabalho. Há, segundo os proponentes do evento, uma tentativa de promover através do skate, a inclusão social ${ }^{17}$ “(...) que contribua para afastar o jovem da ociosidade, das drogas e consequentemente do crime" ${ }^{18}$. Ao apontar alguns benefícios do circuito, o skatista Alexandre "Nicolau" afirma:

Eu acredito que [o Circuito Sampa Skate] é uma parada positiva para o skate. É uma coisa que não tem. É um evento com uma estrutura bacana. Tem uma estrutura que campeonato pago não tem, é uma iniciativa gratuita. Se o cara tem a curiosidade de ir lá e experimentar, ele vai experimentar, vai saber o que é correr um campeonato. E vêm pessoas de qualquer lugar (Entrevista em 26 de março de 2010).

A criação do ranking é, de certo modo, uma tática dos próprios organizadores para que os skatistas participantes do Circuito Sampa Skate se sintam motivados a fazer um planejamento de suas atividades ao longo do ano. Não basta somente andar de skate e ir aos campeonatos. É preciso também saber administrar a própria vida como skatista, traçando metas e objetivos bem definidos. A partir do momento em que o jovem começa a participar do circuito, há uma tentativa de disciplinarização não só da prática do skate, como também de sua vida pessoal. Por isso as regras devem ser seguidas a risco e saber se relacionar com elas é essencial. Perguntei a Tanabe que tipos de regras são essas e ele esclareceu:

Regras desde ler o regulamento: "duas voltas de 60 segundos. Văo para final os cinco melhores da eliminatória mais os cinco melhores da semifinal". Que é uma coisa que o skatista tinha mania de não ler (...). Mas no começo do "Sampa", a gente identificava esta dificuldade dos caras lerem o regulamento, de acessar a Internet e escrever os dados na ficha e tal (Entrevista em 22 de outubro de 2009).

O site do Circuito Sampa Skate contém todas as principais informaçôes para os skatistas, que vão desde o calendário com as datas das etapas, resultados, fotos, classificação no ranking até vídeos com a volta de alguns competidores. Aqueles que participam do circuito devem conhecer todas as informações, principalmente suas classificaçóes para, a partir delas, elaborar as estratégias que visem alcançar boas colocações no ranking final. Ao calcular a média dos pontos alcançados, o skatista saberá se precisa tirar melhores colocaçóes nas próximas etapas ou somente se manter como está:

[O skatista tem] que entender o que é descartar resultado, como se faz a conta, como se calcula 
De SKATE PELA CIDADE: QUANDO O IMPORTANTE É (NÃO) COMPETIR | I79

uma média. O cara vai entender que a aula de Matemática serviu para alguma coisa! E vai servir o tempo inteiro: na hora de comprar um carro, na hora de comprar uma casa, para ele entender quanto vale o salário dele, na hora de planejar a vida dele. É uma brincadeira de planejar a vida. Qual o tempo de vida que o jovem imagina que vai ter? Ele nem imagina (...). Aí você tem um novo jeito de falar isto. Por exemplo: você tem quinze etapas. Das quinze etapas você pontua com seus seis ou sete melhores resultados, e vai descartar os outros. Aí você faz média, pode estar entre os quarenta. O Top 40 é formado por vinte cinco daqui... É parecido com uma questão de vestibular (Márcio Tanabe, entrevista em 22 de outubro de 2009).

Propiciar o planejamento e ocupar a mente dos skatistas com objetivos. Essa é a ideia dos organizadores ao criarem os referidos tipos de regras. O skate, desse ponto de vista, seria um meio de estimular o raciocínio, de organizar a conduta e de tirar os jovens do ócio. Para o skatista Everton Canuto ${ }^{19}$ :

[O Circuito Sampa Skate] é um projeto social para mostrar para a galera que o skate está em alta, abrindo portas, tem grandes talentos. Abrindo portas para o cara ocupar a mente, ver que o skate não é quatro rodas, o truck e a madeira (Entrevista em 26 de março de 2010, grifos meus).

Rogério “Tilskater” também corrobora com a visão dos organizadores:

De uma certa forma tem uma inclusão social. Você tira alguém da rua, você tira o moleque de alguma coisa que ele poderia estar fazendo errado (Entrevista em 4 de outubro de 2009).

O tempo ocioso, que em outros estudos de práticas esportivas e de lazer é analisado em oposição ao mundo do trabalho, nesse caso se manifesta também em oposição ao tempo escolar. De acordo com Spaggiari (2009, p. 51), em sua dissertação de mestrado sobre a prática futebolística em escolinhas de futebol em regióes periféricas da cidade de São Paulo, existe, na visão de diferentes atores sociais, "um tempo não-escolar perigoso, estimulador da violência e da desordem, o que exigiria como solução a ocupação do mesmo por meio da prática futebolística", ou, nesse caso, por meio da prática do skate. A rua, portanto, seria o local onde se vivencia o tempo ocioso perigoso. Sendo assim, são comuns políticas públicas com o propósito de "tirar os jovens da rua” por meio de uma prática esporti$\mathrm{va}^{20}$. Mas no caso do street skate, como será visto ao final deste artigo, essas açóes podem ter um efeito reverso: em vez de tirar o skatista da rua, incentiva-o ainda mais a ir até ela, para vivenciar certos tipos de experiências compartilhadas no universo da prática em que ele está inserido ${ }^{21}$.

Como parte das políticas públicas voltadas à prática do skate manifesta através do Circuito Sampa Skate, os melhores competidores, com base no ranking final, ainda possuem a chance de pleitearem a Bolsa Atleta, benefício do Governo Federal que concede ao skatista uma quantia em dinheiro por mês para se dedicar ao esporte. A quantia serve, na maioria das vezes, como suporte para ser utilizada em eventuais gastos como, por exemplo, a compra de peças para o skate, viagens, participaçáo em outros campeonatos etc. Portanto, por mais que o circuito não ofereça inicialmente nada de muito vantajoso para os skatistas, ao seu final, aqueles que melhor projetarem as atividades durante 
o ano, poderão ser recompensados com a premiação do "SP Top 40", um curso profissionalizante e a Bolsa Atleta.

Após todas as consideraçôes, é possível notar como certos projetos têm sido concebidos especificamente para a prática do street skate na cidade de São Paulo. Tiago Lobo pontua que o poder público tem procurado investir não só em eventos que são meros "espetáculos", mas também na formação de novos "skatistas cidadãos":

A gente trabalha nas três instâncias. No esporte educacional, no esporte radical. No skate, a base, as "aulinhas". A gente tem vinte e três Clubes Escolas, que dão aula de skate gratuita, pagas pela prefeitura. Os eventos localizados de pequeno porte, que são os eventos na pista, "eventinho" pequeno, mais regional. Os de médio porte: um Sampa Skate; um SkateBanks; um Universitário; a Virada Esportiva; o Skate no Museu; o Slalom em Interlagos, que são nem tanto para os iniciantes e não são nem tanto localizados. Amador, Pro [profissional] e espalhado, que agrega ao público da cidade e ao público praticante em geral, no país inteiro. E o de grande porte, que é um investimento mais alto, que dá um retorno de mídia mais alto, que é a Mega Rampa e os $\mathrm{X}$ Games (Entrevista em 7 de outubro de 2009).

As políticas públicas para o skate se dão a partir de três instâncias, que vão desde a base (escolinhas de skate em pistas), passando por eventos direcionados aos praticantes, até espetáculos de grande visibilidade, voltados não só para um público skatista. O Circuito Sampa Skate, dentro dessa concepção fornecida por Tiago Lobo, é um evento de médio porte.

Embora o circuito seja formatado para estimular a competitividade, a partir dele também se tem, na perspectiva dos skatistas, uma situação favorável para socializar e paralelamente inserir o jovem no contexto da cidade, uma vez que os campeonatos permitem a ele um contato na vida social de sua localidade e para fora dela, em conseqüência das redes de relaçóes que são tecidas e ampliadas:

Conheci bastante gente. Gente que eu nem imaginava conhecer eu conheci. Troco idéia e tenho um relacionamento até hoje, trocando idéia pela Internet, marcando sessâo para fazer alguma foto (Rodrigo "Bocão", entrevista em 17 de março de 2010).

Cada etapa num lugar diferente, situação diferente, é bem bacana. Estive em lugares que nem sonhava em ir. Se não fosse o "Sampa" eu não teria ido (Alexandre "Nicolau", entrevista em 26 de março de 2010).

Levando em conta os discursos de agentes ligados ao poder público, e também, os dos próprios participantes, pode-se concluir que em cada etapa do Circuito Sampa Skate, ao mesmo tempo em que se tem a oportunidade de familiarizar o skatista com seus pares, de discipliná-lo, de incentivá-lo a praticar o skate em locais "apropriados", também se torna possível um novo estranhamento, a redescoberta de novos territórios, a inserção em novos contextos, propiciando-o a participar de interaçóes que o aproximam ou o distanciam de outros citadinos ${ }^{22}$.

\section{O útil e o agradável}

Campeonatos que contam com o apoio do poder público - como o Circuito Sampa Skate - geralmente são formatados para a disciplinari- 
zação do skate. Por implicarem o cumprimento de regras pré-estabelecidas, supóe-se que esses eventos reservem pouco espaço para a criatividade e o prazer que a prática propicia. Afinal, apenas poucos minutos em cima do "carrinho" 23 durante a competição não possibilita, até certo ponto, realizar tantas manobras, muito menos mostrar a competência, de fato, que o skatista possui. O principal, nesse caso, é a eficácia. Para alcançá-la é preciso adotar estratégias que visem, sobretudo, fazer as manobras com perfeição. Qualquer erro, devido ao grande número de competidores, pode ser crucial nas competiçóes.

Contudo, ao participarem do Circuito Sampa Skate, os skatistas ressignificam as intençôes iniciais propostas pelos organizadores, fazendo dos eventos muito mais que uma simples competição esportiva repleta de regras. Por isso não é raro ouvir frases como "o 'Sampa' é uma festa" ${ }^{24}$. Ainda que os participantes levem a sério a competição, boa parte daqueles que ali estão prioriza e cria discursos em torno do caráter lúdico que as disputas e as diversas formas de sociabilidade estabelecidas propiciam. Tanto que alguns skatistas subvertem o caráter competitivo formatado e entram na pista para zombar, para demonstrar um tipo de desempenho que não é compatível com a performance esperada pelos espectadores.

Por mais que os campeonatos envolvam aspectos utilitários em suas realizaçôes, são neles que os skatistas também podem romper com a rotina de seus cotidianos, deixando de lado, momentaneamente, o mundo do trabalho, da escola e das demais obrigaçóes a que estão sujeitos. Mas também há aqueles que tentam estabelecer uma ponte entre o lazer e o trabalho25, entre o descompromisso e o compromisso, entre o lúdico e o utilitário. É a junção "do útil e do agradável" que faz com que o skate possa ser visto como uma espécie de transição entre diferentes mundos ${ }^{26}$, mediante as intençóes e os objetivos de cada um dos skatistas:
Eu sempre corri [campeonatos] por causa de amigos, todo mundo ir e falar: "todo mundo anda junto, vamos ir e correr”. E foi pela diversão em si, de andar com os amigos em campeonatos. Lógico que todo mundo quer ganhar o prêmio, ser o primeiro lugar. Mas eu sempre vi campeonato como uma festa, um evento onde a gente vai para andar de skate e se divertir. Nem sempre você se lembra do cara que ganhou, mas você se lembra daquele cara que deu aquela manobra. Sempre corri para me divertir (Alexandre "Nicolau", entrevista em 26 de março de 2010, grifos meus).

Fui participando [do Circuito Sampa Skate] e acabei até me empenhando, para falar a verdade. Para ficar entre os primeiros, para conseguir a Bolsa Atleta. Unir o útil ao agradável, ganhar um dinheirinho aí se divertindo (Alexandre "Nicolau", entrevista em 26 de março de 2010, grifos meus).

As falas de Alexandre "Nicolau" resumem bem os aspectos apresentados. Como vimos, os skatistas possuem um ou vários tipos de motivaçôes no momento em que participam dos campeonatos. Lá expressam diferentes tipos de corporalidades, de preferências, de gostos, entre outras distinções, que orientam também as formas de sociabilidade tecidas e alargadas a partir de cada etapa.

\section{"Agora vou andar de skate de verdade"}

As etapas do Circuito Sampa Skate terminam, mas isto não quer dizer que os skatistas percam os contatos estabelecidos. Eles saem do local de competição na companhia dos outros, e aqueles que não conseguem carona para ir embora, vão em direção ao ponto de ônibus ou estação de metrô mais próxima. Tive a oportunidade de acompanhar vários desses 
momentos. Como as etapas acontecem em regiôes distantes do Centro, os skatistas, para se localizarem mais facilmente, pegam alguma condução que passe em uma área de fácil acesso a todos. Desse modo, vários deles circulam juntamente pela cidade, até certo ponto em que se dispersam. E durante o trajeto, alguns ainda têm fôlego para andar ainda mais de skate, desta vez não em uma pista, mas nas ruas.

O skatista Alexandre "Cotinz", ao ir embora da $1^{\text {a }}$ etapa foi andar de skate em alguns equipamentos públicos da cidade, junto de seus amigos. Antes de partir, ele me disse: "estou indo andar na rua. Agora vou andar de skate de verdade..." (Grifos meus). E não foi só esse skatista que conferiu importância ao skate praticado nas ruas. Vários outros me disseram que participam do Circuito Sampa Skate, que é um campeonato realizado em uma pista, mas nem por isso andam somente ali, pois preferem as ruas. Alexandre "Nicolau", freqüentador assíduo das etapas, confessa que:

[O Circuito Sampa Skate] é legal cara. Mas campeonato não é o foco principal do skate. Acho que é andar de skate na rua, desenvolver um trabalho na rua, que é o verdadeiro street, que é a "modalidade" (Entrevista em 26 de março de 2010, grifos meus).

Rodrigo "Bocão" acredita que, de certa forma, por meio das vivências compartilhadas durante os campeonatos, os skatistas são influenciados a andar nas ruas:

Tem bastante molecada que está começando a andar e não vai muito para os lugares. Ainda não tem aquela meta de sair para os lugares, para fotografar. Mas aí eles vão vendo [o Circuito Sampa Skate] e adquirindo isso aí, de poder sair para a rua para filmar, e gostando cada vez mais do skate. Tem a molecada nova que tipo, foi no campeonato, correu e acho legal. Depois do campeonato vai gostando mais e vai indo [para as ruas] (Entrevista em 17 de março de 2010).

A molecada nova está no campeonato e se conhece. Também têm os outros que estâo na rua fazendo um "trampo". Eles começam a "colar" junto e vão aprendendo outras coisas com as pessoas que estão mais tempo ali andando, fazendo outras coisas também além do campeonato (Entrevista em 17 de março de 2010).

Sandro Sobral, skatista profissional, disse-me que o circuito é uma "porta de entrada" para o universo do street skate tanto para aqueles que almejam vivenciar as experiências em "ser skatista", quanto para aqueles que queiram consolidar uma carreira como profissionais.

\section{Consideraçóes finais}

De uma maneira ampla, têm sido recorrentes as tentativas de consolidação de políticas públicas que visam disciplinar algumas práticas e restringir a sociabilidade tecida em torno das mesmas a espaços definidos de antemão, os quais são considerados, a partir da ótica institucional, como apropriados para tais fins.

Neste artigo foi possível notar que o Circuito Sampa Skate tenta lidar com certas ambigüidades, onde de um lado está envolvido o exercício de uma prática esportiva, e de outro, as implicações em torno dos usos das ruas. Com efeito, os organizadores do circuito, com vistas a disciplinar e regulamentar a prática do street skate, criaram um formato de evento pautado 
na ampliação da cidadania, sendo que essa, de acordo com suas visóes, promoveria a inclusão social. Desse modo, os skatistas possuiriam seus direitos: a construção de várias pistas públicas em diversos pontos da cidade, além do apoio de agentes do poder público para a organização de eventos. E ainda, seus deveres: se há pistas de skate e se os campeonatos acontecem nelas, os skatistas deveriam praticar o skate nesses espaços "apropriados", evitando as ruas.

O site da Skate Contest deixa bem claro um dos sentidos atribuídos à inclusão social que a mesma tenta promover, em parceria com a Secretaria de Esportes, a partir da realização do Circuito Sampa Skate: por meio de uma série de eventos são criadas açóes "(...) que contribua[m] para afastar o jovem da ociosidade, das drogas e consequentemente do crime"27. O Circuito Sampa Skate, através dessa perspectiva, levaria os participantes a manter a "mente ocupada"; portanto, eles são influenciados a levar a sério a competição ao longo de todo o ano, devendo buscar um desempenho satisfatório tendo em vista os benefícios que podem ser conquistados mediante a uma boa colocação no ranking final.

De fato, os skatistas se sentem motivados a participar dessa dinâmica promovida pelos organizadores. Entretanto, como o circuito é itinerante, à proporção que participam de sua realização, eles circulam pela cidade, criam vínculos e atualizam as informaçóes de interesses mútuos com outros participantes. Em meio a tudo isso muitos deles, principalmente os principiantes, também são socializados no universo da modalidade street skate, onde aprendem novos códigos e participam de certas experiências comuns aos outros que ali estão. Desta forma, os skatistas produzem um deslocamento simbólico nos propósitos do circuito: para eles, a inclusão social por meio da prática do skate tem mais a ver com um alargamento da sociabilidade do que com a disputa esportiva propriamente dita. Isso fica evidente durante a realização dos eventos. Através de constantes idas a campo e à medida que se ampliava minha rede de relaçôes, percebi que embora exista a competição, para vários skatistas a mesma é o que menos importa. Em virtude disso, muitos não se intitulam "atletas", e não fazem questão de treinar ou fazer alguma preparação física, pois o mais importante, segundo eles, é "se divertir".

Cada etapa do circuito, realizada durante um final de semana, tem hora para começar, mas não para terminar. Com isso os skatistas, de um modo geral, passam mais tempo com aqueles que são considerados "amigos" que, de fato, andando de skate. Em certos instantes a competitividade é diluída para muitos (embora não seja extinta), dando margens ao estabelecimento de relaçóes e associaçóes com vários outros participantes do evento que são, ao mesmo tempo, competidores e espectadores. Nos campeonatos os skatistas criam formas de sociabilidade que propiciam arranjos em suas associaçóes ${ }^{28}$, que os deixam "todos juntos e misturados" ${ }^{29}$. De acordo com o interesse da situação os mesmos ligam-se ou desligam-se de novos relacionamentos, que são efêmeros ${ }^{30} . \mathrm{Na}$ presença de competidores de várias localidades, os contatos são ampliados. Geralmente mantidos pela Internet, através deles os skatistas marcam encontros para andar de skate juntos, embora não somente em pistas e em regióes periféricas, mas também nas ruas e em regióes centrais da cidade, em locais como Vale do Anhangabaú, Parque do Ibirapuera, Avenida Paulista, dentre outros.

Se para o poder público a cidadania se aproxima, de certo modo, do conceito de civilidade, para os skatistas - ou, para ser mais específico, para os streeteiros - a condiçâo de cidadão está mais relacionada à sociabilidade e, 
portanto, à de citadino. Conforme demonstrei em minha dissertação de mestrado (Machado, 2011), há ainda uma espécie de repulsa a uma sociabilidade confinada a espaços que dispóem de certas regras, como as pistas, em prol da valorização de seu alargamento por toda a cidade. Sendo assim, sujeitar esses citadinos às competiçóes com normas precisas, sendo muitas delas morais, e também, confiná-los somente em espaços construídos especialmente para a prática esportiva, não detém os devires do universo da modalidade street skate.

Com o andamento do trabalho de campo foi possível observar que a prática do street skate não é facilmente identificável somente com pontos definidos da cidade. Ela pode ser vista em muitos lugares, não definidos de antemão. Dessa maneira, ao circular pelo meio urbano tendo em vista a procura por picos, a cidade é ordenada a partir das experiências diversificadas dos skatistas.

Ao acompanhar a realização do Circuito Sampa Skate durante o ano de 2009, também foi possível compreender como os skatistas constroem redes mais amplas de relaçóes, por meio da constituição de sociabilidades alargadas $^{31}$ (Agier, 1999), onde "se estabelecem níveis intermediários de vida social, situados entre o mundo doméstico de tais citadinos e as instituições ou macroestruturas mais abrangentes" (Frúgoli Jr., 2007, p. 50). Através de uma série de mediaçóes sociais os skatistas tornam-se mais urbanos; logo, partindo de Agier (1998, p. 61), as formas de sociabilidade criadas em torno da prática do street skate se configuram enquanto mediadoras entre estes citadinos e a cidade.

Levando em conta as aproximaçóes e distanciamentos (Simmel, 1983) dos habitantes da cidade ${ }^{32}$ e o caráter relacional apresentado em torno do universo do street skate, concluise que as práticas citadinas incorporam ou englobam as práticas de cidadania no contexto urbano. Conforme se evidenciou neste artigo, os skatistas citadinos se beneficiam das alternativas fornecidas pelo poder público (como os campeonatos e as pistas) e se posicionam politicamente diante suas demandas. Todavia, por mais que participem das competiçóes e pratiquem em espaços “apropriados”, eles não deixam de ir para as ruas, onde para muitos se anda de skate de "verdade", pois são nelas em que podem fazer uma parte de seus "trabalhos", como a captação de imagens para a mídia especializada, e também, onde se vivencia aquilo que é apontado como primordial no skate, ou seja, a "diversão" em companhia de outros. Portanto, os skatistas, seja em suas condições de cidadãos ou citadinos, buscam conquistar a cidade por meio de seus múltiplos discursos, relaçóes e práticas cotidianas vividas em situação.

\section{Skateboarding through the city: when the} important thing is (not) to compete

abstract This article examines how the skateboarders relate their practices to the practices of citizenship to which they are subjected in Sao Paulo. Skateboarding can be considered one of the sports that most gained visibility in recent times. Despite all the popularity gained, skateboard is also a source of controversy because of the troubles arising from his practice in areas deemed "inappropriate". This and others actions have motivated intense discussions in Sao Paulo, leading many agents linked to the government to develop certain actions in order to discipline the use of skateboards in the streets. One of these actions is the Circuito Sampa Skate, whose format and mediations established for their implementation can be seen as a form of response from the public politics of the sport to the intense propagation of street skate in the city.

keywords Skateboard. Urban spaces. Sociability. Citizenship. Cities. Anthropology of city. 


\section{Notas}

* Este artigo contém resultados da pesquisa realizada para minha dissertação de mestrado, intitulada "De 'carrinho' pela cidade: a prática do street skate em São Paulo", orientada pelo Prof. Dr. Heitor Frúgoli Jr., e defendida no Programa de Pós-Graduação em Antropologia Social da Universidade de Sáo Paulo (PPGAS/USP) no ano de 2011. A pesquisa contou com o financiamento do CNPq em seus primeiros meses de execução e, posteriormente, da FAPESP.

1. Resultados dessa pesquisa foram publicados na Revista CemporcentoSkate (edição 15, 2010).

2. Disponível em: http://www1.folha.uol.com.br/folha/esporte/ult92u102808.shtml. Acesso em 30 de maio de 2011.

3. Lei $11.812 / 1995$.

4. Lei 684/2003.

5. Para uma análise mais detida sobre a questão do espaço urbano, vide Frehse \& Leite (2010). Esses autores fizeram um levantamento bibliográfico das principais discussōes referentes à temática "espaço urbano no Brasil", apresentando diversas concepçōes sobre o assunto, que são mobilizadas, em termos teórico-metodológicos, de diferentes modos.

6. "Andar de skate" é uma expressão nativa que designa a prática do skate.

7. Para mais consideraçôes a respeito da dimensão da "diversão" e do "trabalho" relacionada à prática do skate, vide Bastos (2006) e Machado (2011).

8. O vereador Adolfo Quintas (PSDB) formulou o projeto de lei $n^{\circ} 116 / 2009$, de 05 de março de 2009, que objetivava proibir a utilização de skates nas calçadas do município de São Paulo. A elaboração desse projeto de lei foi motivo de polêmica, levando o vereador a recuar com seus objetivos. Para informaçóes sobre a tentativa de proibição do skate nas ruas de São Paulo, vide Brandão (2011) e Machado (2011).

9. Agentes ligados principalmente à Secretaria de Esportes do Município de Sáo Paulo, tal como apresentado no decorrer do artigo.

10. Não é meu objetivo fazer neste artigo uma discussão conceitual de cidadania. Para uma análise mais aprofundada sobre o termo nas Ciências Sociais, ver Schritzmeyer (2006).

11. Durante o ano 2009 acompanhei diversas etapas do Circuito Sampa Skate, realizadas em diferentes regiōes da cidade de São Paulo. Ao longo do trabalho de campo focalizei as práticas e os discursos não só de skatistas amadores e profissionais, mas também de profissionais da mídia especializada, agentes do poder público, empresários, dentro outros. Mais detalhes sobre o trabalho de campo com o universo do street skate paulistano pode ser visto em Machado (2011).

12. Michel Agier (2011, p.32) defende a possibilidade e a utilidade de três aspectos distintos (mas convergentes) como modo de entendimento de uma antropologia $d a$ cidade: os saberes (les savoirs); os espaços (les espaces) e as situaçōes (les situations). Desse modo, o mesmo autor postula que a antropologia $d a$ cidade não se baseia numa definição externa, urbanística, estatística ou administrativa da cidade, mas ao contrário, leva em consideraçáo o seu caráter de uma multitude sem totalidade. Para mais referências sobre Antropologia da Cidade, vide Frúgoli Jr. (2005; 2007) e Eckert (2010).

13. Para informaçóes sobre os desdobramentos e a trajetória do conceito de situação na Antropologia, ver Frúgoli Jr. (2007).

14. Skatepark é o espaço onde se localiza a pista de skate.

15. Os Centros Educacionais Unificados (CEUs) são equipamentos públicos criados pela Prefeitura de São Paulo, durante a gestão da referida prefeita Marta Suplicy, localizados em áreas periféricas da cidade.

16. Para Sierra (2005), o discurso dos especialistas - como o de Márcio Tanabe em relação ao skate - legitima-se através da competência técnica verificada com base no conhecimento que eles são capazes de demonstrar ou que podem produzir acerca dos problemas urbanos. Com isso eles garantem "um espaço de influência na elaboração de políticas públicas. Trata-se menos de um trabalho vinculado à representação, do que um esforço de planejamento, que envolve o emprego de uma racionalidade capaz de indicar a melhor distribuição e aplicação dos recursos financeiros" (Sierra, 2005, s/p).

17. Conforme as constantes conversas que tive com os skatistas, percebi que nem todos aspiram ser skatistas profissionais. Alguns pretendem se tornar fotógrafos de revistas especializadas, videomakers ou donos de marcas de produtos para skate. Dito de outra forma, o importante é, dentro dessa concepção, fazer algum tipo de atividade profissional que esteja relacionada ao skate.

18. Disponível em http://skatecontest.com.br/. Acesso em 20 de janeiro de 2010.

19. A partir do ponto de vista desses atores pode-se pensar que os skatistas são levados a estabelecer algum 
tipo de projeto, que "sendo consciente, envolve algum tipo de cálculo e planejamento, não do tipo homo oeconomicus, mas alguma noção, culturalmente situa$\mathrm{da}$, de riscos e perdas quer em termos estritamente individuais, quer em termos grupais" (Velho, 2004, p. 29). Para Gilberto Velho (2003, p. 28) ainda, no nível individual, o projeto "lida com a performance, as exploraçôes, o desempenho e as opçôes, ancoradas a avaliaçôes e definiçóes da realidade”.

20. Diversas iniciativas promovidas pelo poder público visam "tirar as crianças e os jovens das ruas" por meio de algum tipo de prática. Hikiji (2006, p. 24), por exemplo, ao analisar o fazer musical por parte de crianças e jovens participantes do Projeto Guri, na cidade de São Paulo, já apontava que no senso comum há uma atribuição de valor negativo ao tempo livre, isto é, ao período fora da escola, onde o momento "ocioso" é entendido como um tempo "perigoso". Em virtude disso, de acordo com a autora, é preciso "ocupar o tempo" das crianças e jovens, é preciso "tirá -los da rua”. Nesse sentido, as propostas do Circuito Sampa Skate, embora sejam destinadas a uma prática esportiva, se aproximam daquelas encontradas no Projeto Guri, tal como estudada por Hikiji (2006).

21. Hikiji (2006, p. 192), novamente em sua pesquisa sobre o Projeto Guri, também reconhece que "diferentemente do tempo ocioso - nunca desejado -, a rua é valorizada em algumas formas de sociabilidade juvenil na periferia”. A valorização das ruas no universo do street skate pode ser vista em Machado (2011).

22. Em sua análise sobre um programa esportivo destinado a comunidades de baixa renda, realizado na década de 1980, Zaluar (1994, p. 65) ressalta que a criação de espaços de sociabilidade resulta na "ampliação do horizonte social dos jovens que acabam saindo do círculo familiar mais estreito, da rede de vizinhos mais próximos, da sua rua ou praça para o bairro, ou seja, de redes de sociabilidade que vão integrá-los à cidade". Essa "ampliação de horizontes" dos jovens participantes do programa esportivo analisado por Zaluar se aproxima, de certo modo, ao alargamento da sociabilidade estabelecida a partir da participação dos skatistas no Circuito Sampa Skate.

23. "Carrinho" é um dos termos nativos que se refere ao "skate".

24. Diante desse clima festivo "teríamos então uma ruptura simbólica e performática com a dimensão temporal propriamente dita, no que segue, ao menos, a da vida ordinária” (Toledo, 2007, p. 263). Faço essa afirmação em relação ao caráter festivo do circuito, com base nos discursos dos próprios interlocutores, sejam eles skatistas, envolvidos com a organização, entre outros, que sempre evocam o termo "festa".

25. Para alguns interlocutores, esse fato torna-se ainda mais nítido: o skate é um meio de diversão, mas também é uma forma de trabalho. Portanto, como ouvi de um skatista, "trabalhamos com aquilo que dá prazer".

26. Com base no trabalho de campo realizado, percebe-se que o skate - para usar uma terminologia de Archetti (2003), tal como discutida por Toledo (2009) - pode ser visto como detentor de um princípio simbólico híbrido, situando-se nos interstícios do lazer e do esporte; do lúdico e do competitivo; do amadorismo e do profissionalismo; do marginal e do socialmente aceito; do público e do privado; do prazer e do risco. O skate é praticado de distintas maneiras e com as mais diversas intençōes.

27. Disponível em http://skatecontest.com.br/. Acesso em 20 de janeiro de 2010.

28. Os arranjos criados pelos skatistas, de certa maneira correspondem a "uma forma específica de se expor, estabelecer laços, marcar diferenças, fazer escolhas, colocar-se, enfim, na paisagem urbana diante dos outros e em relação a eles" (Magnani, 2007, p. 253).

29. Essa frase foi dita por diferentes interlocutores ao longo do trabalho de campo.

30. Sobre novas consideraçóes a respeito das formas de sociabilidade estabelecidas em campeonatos de skate, vide Machado (2012).

31. Estes domínios das sociabilidades alargadas, que se baseiam nas dinâmicas das redes, de uma forma ampliada levaria, em última instância e numa perspectiva totalizante, "à própria compreensão da cidade enquanto 'rede das redes' (como já aventara Hannerz), mesmo que isso se trate, admite o autor, de um horizonte metafórico, impossível de uma reconstituição antropológica” (Frúgoli Jr., 2007, p. 50-51).

32. Georg Simmel (1983), no começo do século passado já chamava a atenção em suas publicaçôes, para a dimensão espacial e relacional das cidades através da noção de mobilidade, a qual se manifesta a partir da figura do estrangeiro - ou estranho - como uma forma específica de interação que articula a noção de proximidade e distância nos relacionamentos estabelecidos (Frúgoli Jr., 2007, p. 16). Nesse sentido, o indivíduo está concomitantemente perto e longe, condiçóes que se manifestam por meio de uma proximidade corporal e uma distância espiritual. Isso o leva a 
De SKATE PELA CIDADE: QUANDO O IMPORTANTE É (NÃO) COMPETIR | I 87

ter mobilidade não só pelos espaços da cidade, mas também, em suas interaçôes, as quais lhe propiciam um estranhamento, a constituição de formas de associaçóes, a mediaçóes, bem como o conflito com os outros. Partindo dos postulados de Simmel (1983), a etnografia do universo do street skate tenta evidenciar esse caráter de proximidade e distância que emerge em meio a uma dinâmica relacional construída a partir do exercício de uma prática esportiva.

\section{Referências bibliográficas}

AGIER, Michel. Lugares e redes: as mediaçóes da cultura urbana. In: NIEMEYER, A.M. \& GODOI, E.P. (orgs.). Além dos Territórios: para um diálogo entre a etnologia indigena, os estudos rurais e os estudos urbanos. Campinas, Mercado das Letras, 1998, p. 41-63.

Linvention de la ville. Paris: Ed. des Archives Contemporaines, 1999. 176p.

Distúrbios identitários em tempos de globalização. Revista Mana, Rio de Janeiro, vol. 7, n 2, 2001, p. 7-33.

. Antropologia da cidade: lugares, situaçôes, movimentos. São Paulo: Editora Terceiro Nome, 2011. $216 \mathrm{p}$.

ARCHETTI, Eduardo. Masculinidades. Fútbol, tango y pólo em la Argentina. Buenos Aires: Editorial Antropofagia, 2003. 287 p.

BASTOS, Billy Graeff. Estilo de vida e trajetórias sociais de skatistas: da "vizinhança" ao "corre". 2006. $174 \mathrm{f}$. Dissertação de mestrado em Ciências do Movimento Humano, Universidade Federal do Rio Grande do Sul, Porto Alegre. 2006.

BRANDÁO, Leonardo. A cidade e a tribo skatista: juventude, cotidiano e práticas corporais na História Cultural. Dourados: Ed. UFGD, 2011. 159 p.

ECKERT, Cornelia. Cidade e política: nas trilhas de uma antropologia na e da cidade no Brasil. In: DUARTE, Luiz Fernando Dias (coord. de área); MARTINS, Carlos Benedito (coord. geral). Horizontes das Ciências Sociais no Brasil: Antropologia. São Paulo, ANPOCS, 2010, p. 155-196.

FREHSE, Fraya; LEITE, Rogério Proença. Espaço urbano no Brasil. In: MARTINS, Heloisa Helena T. de Souza (coord. de área); MARTINS, Carlos Benedito (coord. geral). Horizontes das Ciências Sociais no Brasil: Sociologia. São Paulo, ANPOCS, 2010, p. 203-252.

FRÚGOLI JR, Heitor. O urbano em questão na antropologia: interfaces com a sociologia. Revista de Antropologia, São Paulo, v. 48, n 1, 2005, p. 133-165.

. Sociabilidade urbana. Rio de Janeiro, Jorge Zahar Editor, 2007. 70 p.

HANNERZ, Ulf. Exploring the City: Inquiries toward an Urban Anthropology. Nova York, Columbia University Press, 1980.378 p.

HIKIJI, Rose Satiko Gitirana. A música e o risco. São Paulo, EDUSP, 2006. 256 p.

JOSEPH, Isaac. A respeito do bom uso da Escola de Chicago. In: VALLADARES, Lícia do Prado (org.). A Escola de Chicago: impacto de uma tradição no Brasil e na França. Belo Horizonte/Rio de Janeiro: Ed. UFMG/ IUPERJ, 2005 [1998], p. 93-128.

MACHADO, Giancarlo Marques Carraro. De "carrinho" pela cidade: a prática do street skate em São Paulo. 2011. 268 f. Dissertação de Mestrado em Antropologia Social. Faculdade de Filosofia, Letras e Ciências Humanas da Universidade de São Paulo, São Paulo. 2011.

- Todos juntos e misturados: sociabilidade no pedaço skatista. In: BRANDÃO, Leonardo; HONORATO, Tony (orgs.). Skate \& Skatistas: questôes contemporâneas. Londrina: Ed. UEL, 2012, p. 63-86.

MAGNANI, José Guilherme C. Conclusão: fechando o circuito. In: MAGNANI, José Guilherme C.; SOUZA, Bruna Mantese (orgs.). Jovens na metrópole: etnografias de circuitos de lazer, encontro e sociabilidade. São Paulo, Editora Terceiro Nome, 2007, p. 247-253.

SCHRITZMEYER, Ana Lúcia Pastore. "Cidadania”. Revista Sexta Feira. São Paulo, Editora 34, n08, 2006, p. 229-233.

SIERRA, Vânia Morales. Crise das representaçôes e o déficit da urbanidade. Achegas - Revista de Ciências Politicas. $\mathrm{N}^{\circ}$ 24. Julho/Agosto 2005. Disponível em http://www.achegas.net/numero/vinteequatro/vania sierra 24.htm. Acesso em 01 de junho de 2010.

SIMMEL, Georg. O estrangeiro. In: MORAES, Evaristo (org.). Sociologia: Simmel, São Paulo, Ática, 1983 [1908].

SPAGGIARI, Enrico. Tem que ter categoria: construção do saber futebolístico. 2009. 265 f. Dissertação de Mestrado em Antropologia Social. Faculdade de Filosofia, Letras e Ciências Humanas da Universidade de São Paulo, São Paulo. 2009.

TOLEDO, Luiz Henrique de. Corporalidade e festa na metrópole. In: MAGNANI, José Guilherme C.; SOU-

cadernos de campo, São Paulo, n. 21, p. 171-188, 2012 
ZA, Bruna Mantese de (orgs.). Jovens na metrópole: etnografias de circuitos de lazer, encontro e sociabilidade. São Paulo, Editora Terceiro Nome, 2007, p. 255-266.

TOLEDO, Luiz Henrique de; COSTA, Carlos Eduardo (orgs.). Visão de jogo: antropologia das práticas esportivas. São Paulo: Editora Terceiro Nome, 2009. 279 p.

VELHO, Gilberto. Projeto e metamorfose: antropologia das sociedades complexas. Rio de Janeiro, Jorge Zahar, 2003. 137 p.

. Individualismo e cultura: notas para uma antropologia da sociedade contemporânea. Rio de Janeiro, Jorge Zahar, 2004, 3. ed. 149 p.

ZALUAR, Alba. Cidadãos não vão ao paraíso. Campinas, Ed. UNICAMP, 1994. 212 p.

\section{Materiais de imprensa}

GUIA DE PISTAS. Revista CemporcentoSkate. São Paulo, edição especial, 2006.

REVISTA CEMPORCENTOSKATE. "SP do skate". São Paulo, n 98, 2006.

. “O skate cresce no Brasil”. São Paulo, edição 15, ano $15,2010$.

SARLI, Carlos. "Pista livre”. Folha Online, São Paulo. Disponível em http://www1.folha.uol.com.br/folhal esporte/ult92u102808.shtml. Acesso em 30 de maio de 2011.

SKATEBOARD CONTEST. Sampa Skate. Disponível em http://skatecontest.com.br/. Acessos em 20 de janeiro e 30 de abril de 2010.

SPINOSA, Marcela. "Av. Paulista vira pista de skate". Jornal da Tarde. 11 de julho de 2008. Disponível em http://txt.jt.com.br/editorias/2008/07/11/ger-1.94.4.20080711.25.1.xml. Acesso em 29 de maio de 2010 .

autor Giancarlo Marques Carraro Machado

Mestre em Antropologia Social / PPGAS - USP

Recebido em 30/03/2012

Aceito para publicação em 01/10/2012 